\title{
A REPRESENTAÇÃO SOCIAL DE MEIO AMBIENTE COMO PONTO DE PARTIDA PARA AÇÕES DE EDUCAÇÃO AMBIENTAL: UMA OCUPAÇÃO IRREGULAR COMO ESPAÇO DE EDUCAÇÃO NÃO ESCOLAR
}

\author{
Roberta Soares da Rosa ${ }^{1}$, Karine dos Santos ${ }^{2}$
}

\begin{abstract}
RESUMO
Este artigo trata de estudo a respeito da representação social de meio ambiente presente entre os moradores de ocupações irregulares de periferia urbana. O objetivo foi diagnosticar a representação social de Meio Ambiente sob a ótica dos moradores da Vila Santo André no município de Porto Alegre, Rio Grande do Sul, com a finalidade de orientar as ações de Educação Ambiental realizadas no âmbito não escolar dentro programa "Consumo Responsável II" do Departamento Municipal de Água e Esgoto - DMAE. O investimento em um processo de análise e interpretação das representações sociais constitui estratégia pedagógica a ser considerada na elaboração de propostas de intervenção junto a determinados grupos. A análise aqui proposta revelou outros temas que não estavam previstos nos planos de trabalho. Além disso, refletiu no alcance do objetivo inicial do projeto que era fortalecer a participação dos sujeitos nos processos de organização comunitária, tanto para a manutenção das conquistas de infraestrutura, quando para o investimento coletivo na busca por outras demandas.
\end{abstract}

Palavras-chave: educação ambiental; representação; educação não escolar;

\section{ABSTRACT}

This article study about the social representation through this environment among residents of irregular occupations of urban periphery. The goal was to diagnose the social representation of the Environment from the perspective of the residents of Vila Santo André in the city of Porto Alegre, Rio Grande do Sul, in order to guide the actions of Environmental Education held in non-school setting within the program "Responsible Consumption II "of the Municipal Department of Water and Sewer - DMAE. Investment in a process of analysis and interpretation of social representations is a pedagogical strategy to be considered in the development of intervention proposals close to certain groups. The analysis proposed here revealed other issues that were not foreseen in the work plans. In addition, reflected in the scope of the initial goal of the project was to strengthen the participation of individuals in community organization processes, both for the maintenance of infrastructure achievements, when for collective investment in the search for other demands.

Keywords: environmental education; representation; not education;

\footnotetext{
1 Bióloga e Mestra em Educação pela Unisinos, estudante do curso de especialização em Educação Ambiental - EAD da FURG, pesquisadora do Coletivo de Educação Popular e Pedagogia Social (CEPOPES).

${ }^{2}$ Pedagoga e Doutora em Educação pela Universidade do Vale do Rio dos Sinos. Professora da Faculdade de Educação da Universidade Federal do Rio Grande do Sul. Pesquisadora no Coletivo de Educação Popular e Pedagogia Social (CEPOPES).
} 


\section{INTRODUÇÃO}

O direito a um meio ambiente ecologicamente equilibrado é garantido pela Constituição Federal de 1988, esta mesma lei também reconhece que o meio ambiente é um bem comum e essencial para a qualidade de vida. O meio ambiente é constituído por fatores bióticos e fatores abióticos. Os fatores bióticos compreendem todos os seres vivos e os abióticos são os fatores do ambiente físico que influem sobre o ser vivo: a temperatura, a umidade, o relevo do terreno, etc. Neste sentido, qualquer alteração no meio abiótico pode impactar direta ou indiretamente na qualidade de vida dos seres vivos inclusive dos humanos. Frequentemente as alterações no meio abiótico são provocadas pela interferência humana que vem desde os primórdios da humanidade alterando a paisagem natural para seu estabelecimento e subsistência, erguendo cidades, usufruindo dos recursos naturais como água e madeira por exemplo.

Estas atividades se executadas sem uma reflexão na perspectiva da sustentabilidade ambiental podem resultar em crises ambientais graves como a escassez da água e a elevação da temperatura do planeta. A reflexão sobre a forma que habitamos o planeta está diretamente relacionada às nossas concepções de desenvolvimento econômico, político e social, atualmente vivemos em um sistema capitalista, ou seja, centrado no capital financeiro. O desenvolvimento do capitalismo na sociedade moderna é marcado por crescentes crises, produzindo riscos e conflitos que refletem no crescimento dos índices de desigualdade e risco social, segundo Galeano (2010) "O desenvolvimento, é uma viagem com mais náufragos do que navegantes" referindo-se ao modelo capitalista de desenvolvimento.

O paradigma do Desenvolvimento Sustentável permeia a produção intelectual e está presente na agenda política do mundo contemporâneo de organizações governamentais e não governamentais como alternativa ao modelo capitalista. O debate teve início em 1972 quando a ONU - Organização das Nações Unidas realizou a Conferencia de Estocolmo sobre o Ambiente Humano, incluiu no discurso desenvolvimentista temas como a pobreza e a degradação ambiental. As definições de Desenvolvimento Sustentável preconizam basicamente a ideia de sustentabilidade planetária, um desenvolvimento em que haja harmonia entre a economia, meio ambiente, direitos humanos, cultura, justiça social e justiça ambiental.

A ONU reconhece a educação como estratégia para o estabelecimento do paradigma de Desenvolvimento Sustentável, nesse sentido, estabeleceu a década para a Educação em Desenvolvimento Sustentável entre os anos de 2005 e 2014, nesse período os 
países deveriam organizar estratégias a fim de divulgar, promover e implementar o paradigma de Desenvolvimento Sustentável. No Brasil no ano de 1999 foi criada a Política Nacional de Educação Ambiental Lei 9.795/99 que estabelece A Educação Ambiental como um "componente essencial e permanente da educação nacional, devendo estar presente em todos os níveis e modalidades do processo educativo, em caráter formal e não formal”.

Partilhamos da concepção de Educação Ambiental defendida por Reigota (2010)

Parto do princípio que a educação ambiental é uma proposta que altera profundamente a educação como a conhecemos, não sendo necessariamente uma prática pedagógica voltada para transmissão de conhecimentos sobre ecologia. Trata-se de uma educação que visa não só a utilização racional dos recursos naturais (para ficar só nesse exemplo), mas basicamente a participação dos cidadãos nas discussões e decisões sobre a questão ambiental. (Reigota, 2010, p.11)

O autor também pondera que a noção de meio ambiente é difusa e variada no meio científico e que o mesmo acontece no meio popular, assim, a identificação da representação social de meio ambiente de determinado grupo deve ser o primeiro passo para a elaboração e execução de qualquer trabalho de educação ambiental que venha ser trabalhado com este público.

Neste contexto, o presente trabalho objetivou diagnosticar a representação social de Meio Ambiente sob a ótica dos moradores da Vila Santo André no município de Porto Alegre, Rio Grande do Sul, com a finalidade orientar as ações de Educação Ambiental realizadas no âmbito não escolar dentro programa "Consumo Responsável II" do Departamento Municipal de Água e Esgoto - DMAE.

\section{A VILA SANTO ANDRÉ}

Cerca de $82,6 \%$ do território de Porto Alegre situa-se na região hidrográfica do Guaíba, a vila Santo André está localizada no extremo norte de Porto Alegre, região composta pelos bairros: Anchieta, Farrapos, Humaitá, Navegantes e São Geraldo. A vila encontra-se a menos de um quilômetro das margens do Rio Gravataí, região considerada várzea do rio, ou seja, a área deveria ser um ambiente de banhado, no entanto, a região é extremamente urbanizada com muitas indústrias as margens do rio.

A comunidade da Vila Santo André se instalou na região na década de 1970, durante a construção da ponte Getúlio Vargas que liga Porto Alegre ao município de Guaíba, no período de construção da ponte foram construídas casas provisórias no entorno da obra para abrigar os trabalhadores e a administração da obra, ao concluir a ponte estas 
casas não foram desfeitas sendo ocupada de forma irregular formando as vilas Farrapos, Dona Teodora, Santo André entre outras.

No levantamento realizado em $2014^{3}$ foram identificadas 300 famílias habitando a Vila Santo André, por se tratar de uma ocupação irregular a infraestrutura básica como água encanada, luz elétrica e rede de esgoto esteve ausente na comunidade até o ano de 2014 quando através da organização da Associação de Moradores e a participação da comunidade no Orçamento Participativo a instalação da luz elétrica dentro do Programa Energia Legal ${ }^{4}$ da $\operatorname{CEEE}^{5}$ e da água encanada através do Programa Consumo Responsável II do DMAE foram conquistadas pelas famílias da vila.

Os dois programas citados anteriormente visam a instalação de água e energia elétrica em ocupações irregulares, neste artigo trataremos de ações realizadas dentro do Programa Consumo Responsável.

O Programa Consumo Responsável II é um programa social de abastecimento de água, criado pelo DMAE em virtude da ocupação irregular do solo em Porto Alegre, onde há dificuldades como o uso inadequado da água, o desperdício, perdas físicas e contaminação das redes. É realizado em áreas irregulares e que apresentam grau variável de deficiência na infraestrutura urbana e dos serviços. (Retirado do site do DMAE).

Com o objetivo de desenvolver ações de conscientização da população a respeito do uso correto da água uma equipe composta por uma assistente social, um sociólogo, um técnico em meio ambiente, uma bióloga e uma estagiária de ciências sociais desenvolviam ações educativas como: reuniões, palestras, oficinas e plantão social afim de promover por meio da participação social o envolvimento das pessoas.

Tal programa insere-se no âmbito do que temos defendido como práticas desenvolvidas em espaços não escolares. Os espaços não escolares se constituem como práticas educativas mediadas cujo potencial de desenvolvimento de uma consciência crítica é preponderante no conjunto de suas ações.

Segundo Gohn (2008) os processos educativos que ocorrem fora das escolas se desenvolvem, sobretudo, em organizações não governamentais e movimentos sociais. Acerca de uma teorização a respeito dessas práticas que se desenvolvem em espaços educativos alheios as escolas, Gohn (2010, p. 15) vai dizer que se trata de considerar "a

\footnotetext{
${ }^{3}$ DMAE Programa Consumo Responsável II.

${ }^{4}$ O Programa Energia Legal de regularização de ligações clandestinas em áreas de complexidade social faz parte do plano de combate as perdas da CEEE Distribuição (CEEE-D) com orçamento garantido e uma estrutura de atendimento dedicada a esse processo. Para que a Companhia possa atuar, a área precisa estar regularizada pelo município ou ser declarada de interesse social.

${ }^{5}$ Companhia Estadual de Energia Elétrica.
} 
educação em seu sentido mais amplo, com os processos de formação dos indivíduos como cidadãos”. Esses processos educativos também são reconhecidos conceitualmente como não formais, que corresponde a categorização referente aos fenômenos educativos presentes em nossa sociedade a saber: a educação formal, não formal e informal.

A educação formal como aquela desenvolvida nas escolas, com conteúdos
previamente demarcados; a informal como aquela que os indivíduos aprendem
durante seu processo de socialização - na família, bairro, clube, amigos etc.,
carregada de valores e culturas próprias, de pertencimento e sentimentos
herdados; e a educação não formal é aquela que se aprende "no mundo da vida",
através da troca de experiências, principalmente em espaços e ações coletivos
cotidianas. Há na educação não formal uma intencionalidade na ação, no ato de
participar, de aprender e de transmitir ou trocar saberes. A informal opera em
ambientes espontâneos, onde as relações sociais se desenvolvem segundo gostos,
preferências, ou pertencimentos herdados. (GOHN, 2006)

Há que se ponderar que adotamos, para este texto,o conceito de educação não escolar, pois reconhecemos que a educação não escolar se inscreve num âmbito mais profissionalizado uma vez que, se estabelece na articulação interdiscilinar de maneira institucionalizada, com intencionalidades e objetivos pré-definidos. Segundo Severo (2015, p.562), os espaços educativos não escolares manifestam-se por meio de "processos institucinalizados em diversos setores da sociedade, passando a influenciar de modo mais incidente a formação humana”. Moura, Zuchetti e Menezes (2014, p.88), reconhecem que, “embora a expressão "educação não escolar" seja relativamente nova, o mesmo não ocorre em relação às práticas que vêm sendo desenvolvidas no campo social”.

Moura e Zuchetti (2010) referem que as práticas de educação no campo social se definem por uma concepção ampliada de educação, designando-a como uma prática social que é também um ato político com bases teóricas para uma prática de educação que se constitua, pelas atitudes de abertura e acolhimento e um corpo de saberes interdisciplinares.

Entendemos que a experiência aqui relatada se deu em espaço não escolar em uma comunidade em situação de "vulnerabilidade social" por se tratar de uma ocupação irregular onde direitos básicos como água tratada, energia elétrica e saneamento estiveram ausentes por quarenta anos. As ações foram regidas por um edital com intencionalidades e objetivos claros, além da exigência de aprovação prévia do órgão gestor de planos e relatórios de atividades, assim entendemos como uma experiência de educação ambiental não escolar. 
E-ISSN - 2238-5533

v. 22, n. 1, p. 183-197, 2017

\title{
O QUE É MEIO AMBIENTE?
}

Como citado anteriormente não há consenso sobre a definição de meio ambiente, no entanto achamos pertinente apresentar alguns conceitos que nos orientam e são referência para o desenvolvimento das nossas ações em educação ambiental.

Sauvé (2005) traz uma definição de meio ambiente a partir da visão integradora da natureza e meio social.

\begin{abstract}
A trama do meio ambiente é a trama da própria vida, ali onde se encontram natureza e cultura; o meio ambiente é o cadinho em que se forjam nossa identidade, nossas relações com os outros, nosso "ser no mundo". (SAUVÉ, 2005, p.317)
\end{abstract}

Esta visão integradora também é expressa por Reigota (2010), além disso o autor ressalta que a definição é a partir da percepção dos sujeitos em determinado tempo e espaço.

Defino meio ambiente como o lugar determinado ou percebido, onde os elementos naturais e sociais estão em relação dinâmica e em interação. Essas relações implicam processos de criação cultural e tecnológica e processos históricos e sociais de transformação do meio natural e construído. (REIGOTA, 2010, p.14)

Em se tratando de educação ambiental em espaços não escolares, principalmente desenvolvidas no campo social, é fundamental uma visão de meio ambiente em que a sociedade e a natureza estejam em uma relação de interdependência e que a educação ambiental seja no sentido de uma convivência harmônica tendo em vista a realidade local, nesse sentido adotamos o conceito de representação social para identificar como a comunidade da Vila Santo André entende o meio ambiente.

Segundo Moscovici (1995) o conceito de representação social teve sua origem na sociologia e na antropologia nos estudos de Durkhein e de Lévi-Bruhl e influenciou a teoria das representações infantis de Piaget, da linguagem de Saussure, e na teoria do desenvolvimento cultural de Vigotsky. Segundo Reigota (2010 p.67) foi fundamental a contribuição de Durkhein para a compreensão de como as representações sociais influenciam nas decisões individuais dos seres humanos dentro de uma coletividade, pois Durkhein parte do princípio que "as sociedades agem sobre seus indivíduos independentemente da vontade destes" por isso o autor denominava esse fenômeno como representações coletivas, somente mais tarde o termo representações sociais foi adotado pelos pesquisadores da área (REIGOTA, 2010, p.68). Moscovici (1995) afirma ainda que as representações sociais são evidenciadas em conversações espontâneas onde o saber 
popular e o senso comum são expressos e praticados cotidianamente, além disso, podem ficar evidentes através das práticas religiosas e ideologias por exemplo.

Devido estas características a representação social tem fundamentado trabalhos de educação ambiental, no sentido de captar a percepção de meio ambiente possibilitando ações que se aproximem da realidade concreta definida por Brandão (1999) como:

A realidade concreta é mais que dados ou fatos, tomados mais ou menos em si mesmos. Ela é todos esses dados, todos esses fatos e mais a percepção que deles esteja tendo a população neles envolvida. (BRANDÃO, 1999)

Reigota e Sauvé, são autores de referência nos estudos de representação social do meio ambiente, e para realizar a análise desses estudos criaram categorias de representação.

Reigota (2010) categoriza as representações de meio ambiente em três tipos:

1) Naturalista onde o meio ambiente é entendido como sinônimo de natureza intocada;

2) Antropocêntrico onde o meio ambiente é visto como fonte de recursos naturais para subsistência humana;

3) Globalizante onde o meio é integrado pelo ambiente e a sociedade

Sauvé (2005) apresenta sete categorias de compreensão de meio ambiente e ressalta que a relação com o meio ambiente é culturalmente determinada:

1) Meio ambiente natureza para preservar, respeitar e apreciar;

2) Meio ambiente como recurso para gerir e repartir;

3) Meio ambiente como problema a ser resolvido ou prevenido;

4) Meio ambiente como sistema a compreender e decidir melhor;

5) Meio ambiente como lugar onde se vive para conhecer e aprimorar;

6) Meio ambiente biosfera com a noção de viver junto e a longo prazo;

7) Meio ambiente como projeto comunitário entendido como lugar de cooperação e de parceria;

Tanto na categorização de Reigota (2010) quanto na de Sauvè (2005) o limite entre uma categoria e outra nem sempre está claramente definido, por vezes um mesmo sujeito pode apresentar uma representação social que contemple mais de uma categoria. Sauvé (2005, p 319) afirma que a relação com o meio ambiente se desenvolve mediante um conjunto de dimensões entrelaçadas e complementares. 
A representação social do meio ambiente reflete uma ideologia dominante influenciada pela sua classe social, religião, trabalho, escola entre outros espaços em que as pessoas reproduzem o que aprendem ou o que consideram importante para si e são construídas e disseminadas através da convivência com outros sujeitos e é nesse processo que se estabelece o senso comum, uma variável importante na definição das representações sociais. A fonte para a identificação da representação social de meio ambiente pode ser qualquer forma de expressão que reflita a vida cotidiana, o desenho é muito utilizado para esse tipo de estudo, no entanto, questionários, relatos e entrevistas também podem ser empregados.

\section{METODOLOGIA}

Para realização deste trabalho adotamos os princípios da pesquisa participativa que Brandão e Streck (2006) definem como:

\footnotetext{
"Uma pesquisa que é também uma pedagogia que entrelaça atores-autores e que é um aprendizado no qual, mesmo quando haja diferenças essenciais de saberes, todos aprendem uns com os outros e através dos outros", (BRANDÃO \& STRECK, 2006, P.13)
}

O objetivo principal das ações de educação ambiental do Programa Consumo Responsável era a economia da água, para tanto antes de abordar a importância do uso consciente da água era pertinente a realização de um resgate da representação social de meio ambiente dos moradores da Vila Santo André.

A representação social é necessária para que se possam compreender como os atores sociais constróem o seu modo de ser e estar nesse mundo na sua relação com o meio ambiente. Estas representações influenciam e determinam as práticas sociais. Por isso, analisar as representações sociais a respeito do meio ambiente se faz necessário enquanto uma estratégia pedagógica.

A representação social de meio ambiente dos moradores da vila Santo André foram captadas através de dois instrumentos, um questionário com perguntas fechadas aplicado em 96 moradores, questionando sobre a coleta e separação de lixo, arborização e educação ambiental, e outro utilizando fotografias a partir de uma oficina fotográfica onde no primeiro momento os moradores foram convidados a fotografar o "meio ambiente da Vila Santo André" e num segundo momento as fotos foram apresentadas a comunidade e solicitado que colocassem legendas que descrevessem as fotos ou sentimento que elas despertavam. 
As respostas do questionário foram organizas em Excel e o percentual de respostas calculado.

As fotografias foram analisadas conforme as categorias de Reigota (2010) e as legendas foram classificadas conforme as categorias Sauvé (1995) ambas citadas anteriormente.

\section{RESULTADOS E DISCUSSÃO}

O Departamento Municipal de Limpeza Urbana - DMLU recolhe o lixo, em quase 91\% das casas, os resíduos orgânicos na comunidade. Quanto a separação do lixo 47,9\% não separa o lixo, 45,8\% separa sempre e 6,3\% separa às vezes. Quando questionados se sabiam o que é Educação ambiental 54,1\% responderam que não sabiam de que se tratava. Sobre a percepção quanto a arborização da vila $89,6 \%$ consideraram que a vila não é arborizada.

$\mathrm{Na}$ oficina retratos da Natureza foram tiradas 15 fotos que posteriormente foram comentadas pelos moradores da vila, algumas delas foram comentadas pelos próprios autores durante a oficina, as outras foram apresentadas a moradores em visitas domiciliares.

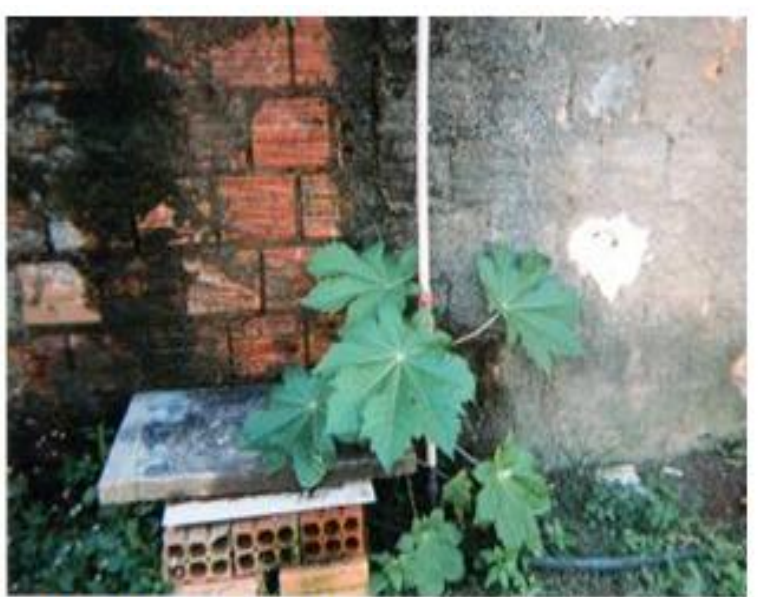

Figura l: autora Jenifer, 11 anos

Precisamos de esgoto, rede de esgoto é saúde! (Nestor, 53 anos)

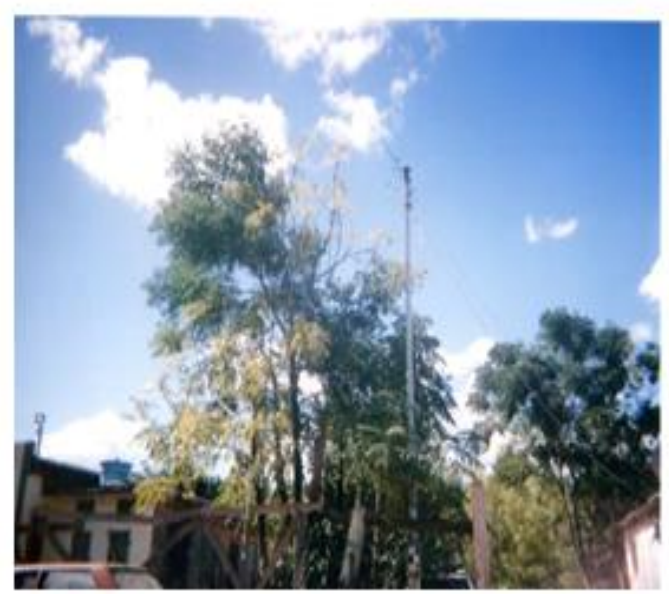

Figura 2: autor Junior Gabriel, \& anos Precisamos cuidar das árvores! (Erica, 35 anos) 
AMBIENTE \& EDUCAÇ̃̃O

ISSN- 1413-8638

E-ISSN - 2238-5533

v. 22, n. 1, p. 183-197, 2017

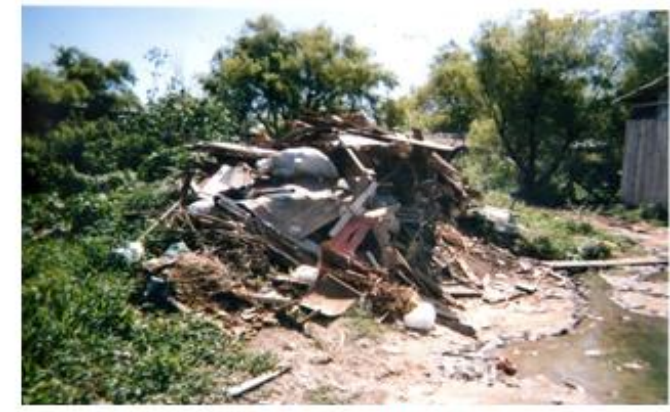

Figura 3: autor Antônio da Silva, idade ñ informada Dois problemas ambientas da vila, o lixo e o esgoto (Glauciomir, 41 anos)

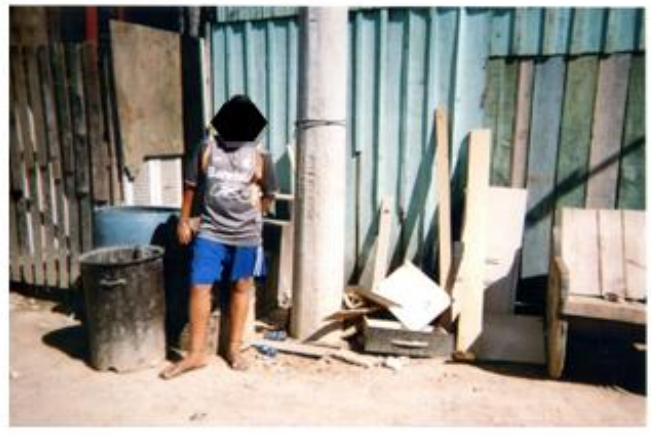

Figura 5: autor Felipe, 12 anos

$\mathrm{O}$ meio ambiente da cidade (mesmo autor)

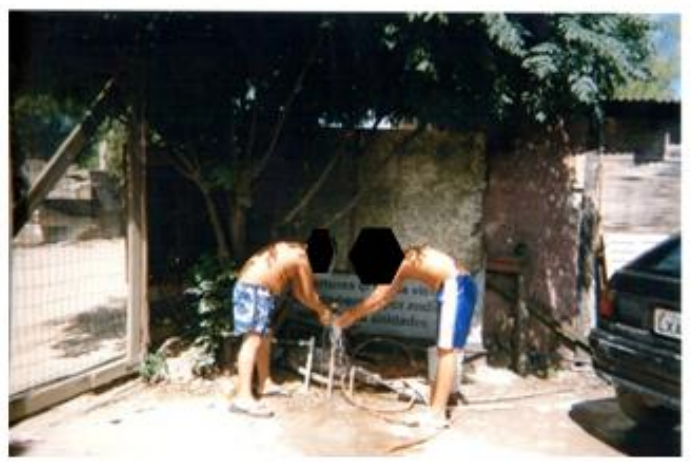

Figura 6: autora Lia, 35 anos

Agua, crianca eárvore, esperanca de um dia melhor (mesmo autor)

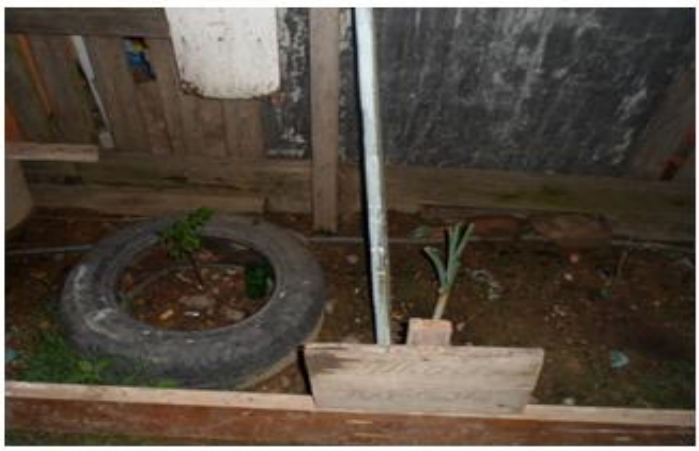

Figura 8: autoras Rafaela e Lorrane, \& e 9 anos Nossahorta, o pai fez a caixa e nós plantamos (mesmas autoras)

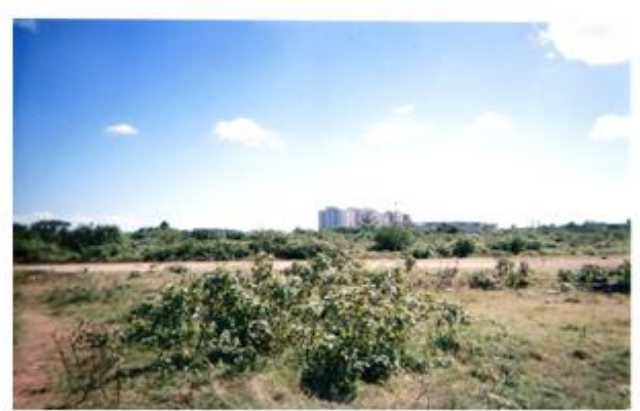

Figura 4: autor Fábio Batista, 19 anos

Tem uns cantos tão bonitos e outros tão feios, esse é un bonito. Quando eu era criança brincava nesse campo (Ana Cristina, 32 anos)

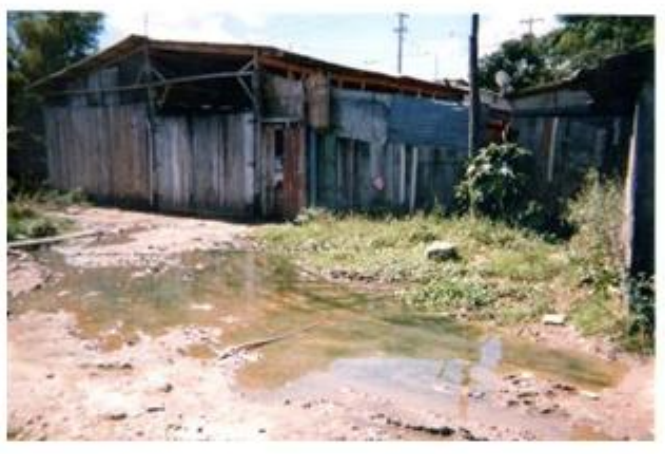

Figura 7: autor Antônio, 58 anos.

Já tem água, já tem luz, agora só falta o esgoto (liovete, 44 anos)

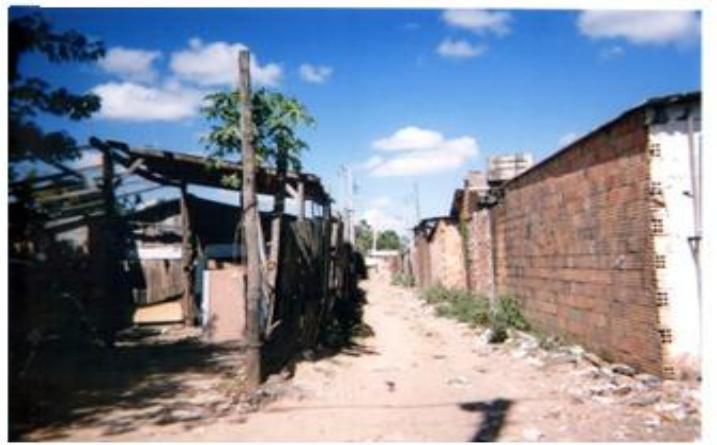

Figura 9: autor Plínio, 61 anos

Quando chove muito barro, quando seco muita poeira, (Cléssio, 16 anos) 


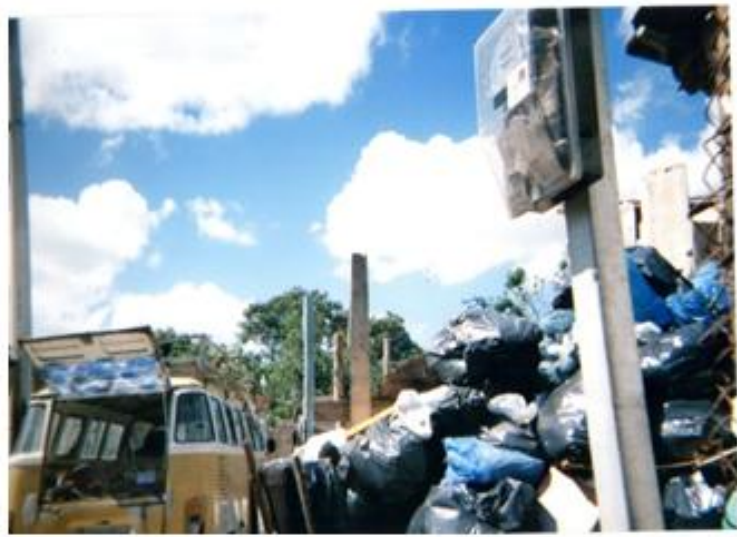

Figura 10: autora Priscila, 7 anos

Essa lixeira precisa mudar e essa mudança depende de nós! (Suelem.25 anos)

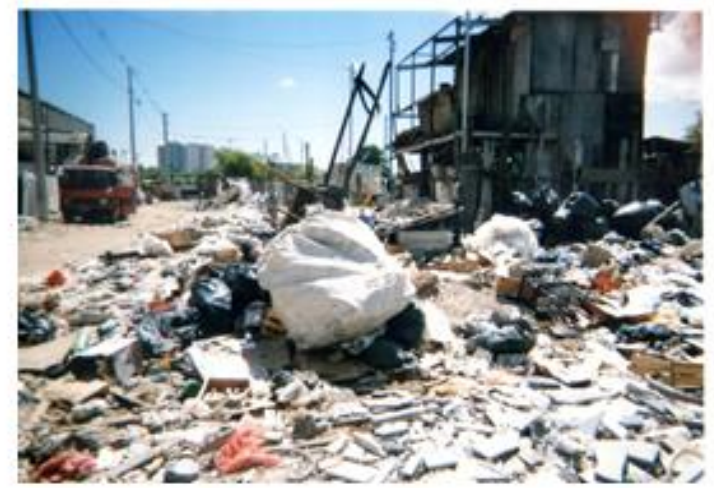

Figura 12: autora Samanta, 13 anos. A reciclagem precisa melhorar, ser mais organizada (Ana Cristina 40 anos)

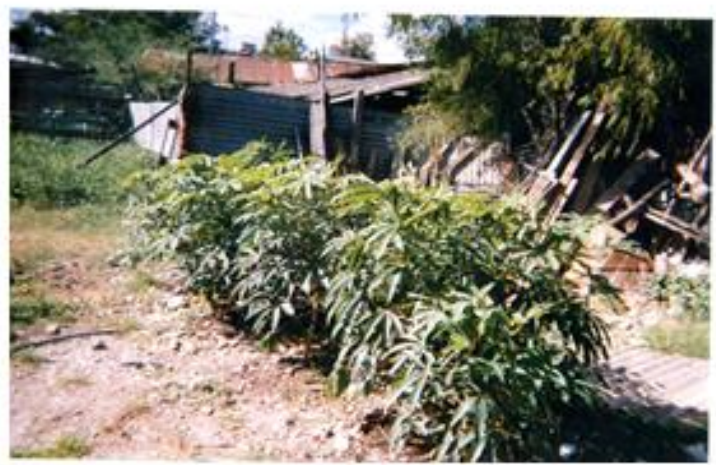

Figura 14: autor Antônio, 67 anos Aipim, produto da natureza que a gente planta, cozinha e come. (Eldelvir, 50 anos)

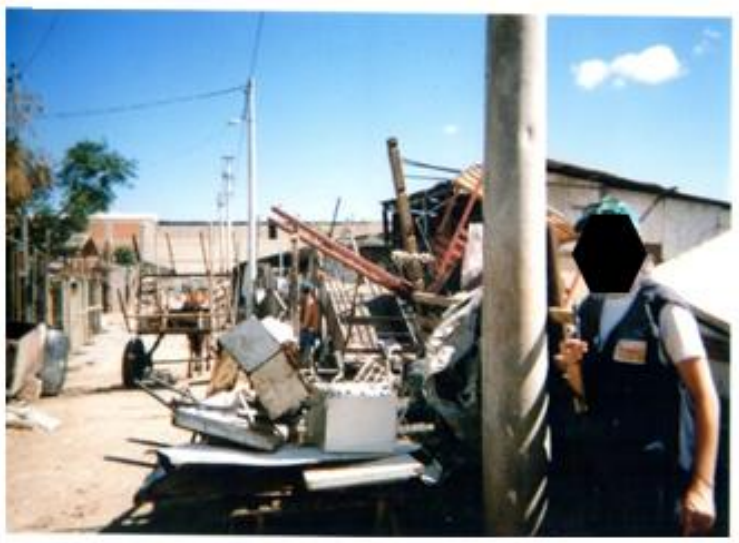

Figura 1l: autor Valter, 39 anos

Trabalhadores lutando pela sobrevivência (Clarinda 47 anos)

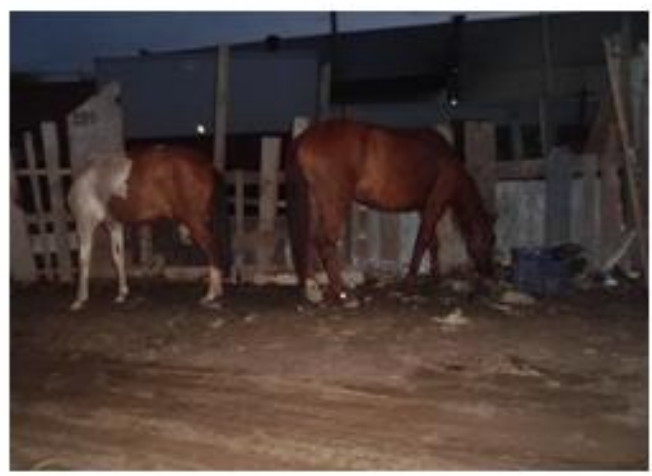

Figura 13: autora Rafaela, 2 anos

Os cavalos fazem bem para o meio ambiente, ajudam no trabalho e transporte (mesma autora)

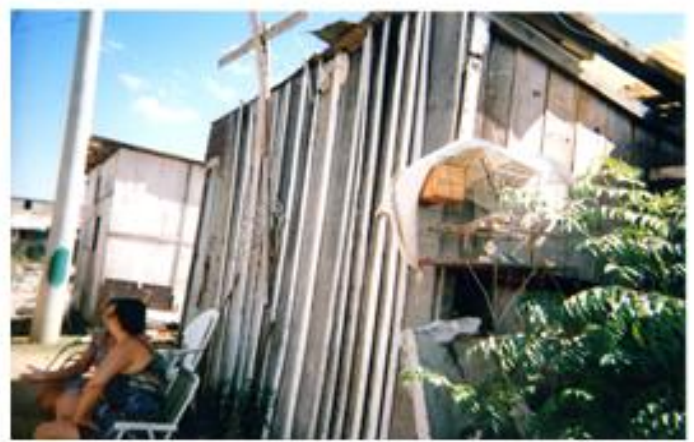

Figura 15: autor Marco Luca, 11 anos

Planta e natureza. (Sadi, idade não imformada)

Como já citamos anteriormente uma mesma imagem pode contemplar mais de uma categoria de representação social, por este motivo optamos pela categorização de Reigota (2010) para esta parte da pesquisa.

$\mathrm{Na}$ análise das fotografias observamos um predomínio da ideia naturalista de meio ambiente, pois a maioria (10 fotos) das imagens foram tiradas em locais em que havia 
vegetação, algum tipo de árvore ou planta. A visão antropocêntrica pode ser observada em cinco fotos, onde aparece animais que são utilizados para o trabalho de recolhimento de resíduos sólidos e transporte, a água como recurso natural a ser utilizado, a plantação de alimentos como o aipim ou mandioca e os próprios resíduos sólidos que são a fonte de renda de algumas famílias da comunidade. A categoria Globalizante foi observada principalmente em três fotos onde a ideia de meio ambiente como espaço de lazer e espaço que precisa ser melhorado com infraestrutura como rede de esgoto transmite a ideia de integração entre ambiente e sociedade, as fotos em que se optou que pessoas aparecessem também trazem essa noção globalizante, pois revela o entendimento de que o ser humano faz parte do meio ambiente.

Já na análise das legendas optamos pelas categorias de Sauvé (2005) por entender que elas especificam de forma mais detalhada as dimensões dos diferentes entendimentos de meio ambiente facilitando a análise do conteúdo.

Tabela 1 Categorias de representação social a partir das legendas das fotos

\begin{tabular}{|c|c|c|}
\hline Categorias & Figuras & Legenda \\
\hline \multirow{2}{*}{$\begin{array}{l}\text { Meio ambiente natureza para } \\
\text { preservar, respeitar e apreciar. }\end{array}$} & 2 & Precisamos cuidar das árvores \\
\hline & 15 & Planta e natureza \\
\hline \multirow{3}{*}{$\begin{array}{l}\text { Meio ambiente como recurso } \\
\text { para gerir e repartir }\end{array}$} & 11 & Trabalhadores lutando pela sobrevivência \\
\hline & 13 & $\begin{array}{l}\text { Os cavalos fazem bem para o meio } \\
\text { ambiente, ajudam no trabalho e transporte }\end{array}$ \\
\hline & 14 & $\begin{array}{l}\text { Aipim, produto da natureza que a gente } \\
\text { planta, cozinha e come. }\end{array}$ \\
\hline \multirow[t]{2}{*}{$\begin{array}{l}\text { Meio ambiente como problema a ser } \\
\text { resolvido ou prevenido }\end{array}$} & 1 & $\begin{array}{l}\text { Precisamos de esgoto, rede de esgoto é } \\
\text { saúde. }\end{array}$ \\
\hline & 3 & Dois problemas da Vila, o lixo e o esgoto \\
\hline
\end{tabular}




\begin{tabular}{|c|c|c|}
\hline & 9 & $\begin{array}{l}\text { Quando chove muito barro, quando seco } \\
\text { muita poeira. }\end{array}$ \\
\hline \multirow[t]{2}{*}{$\begin{array}{l}\text { Meio ambiente como lugar onde se } \\
\text { vive para conhecer e aprimorar }\end{array}$} & 4 & $\begin{array}{l}\text { Tem uns cantos tão bonitos e outros tão } \\
\text { feios, esse é um bonito. Quando eu era } \\
\text { criança brincava nesse campo }\end{array}$ \\
\hline & 5 & O meio ambiente da cidade \\
\hline $\begin{array}{l}\text { Meio ambiente biosfera com a noção } \\
\text { de viver junto e a longo prazo }\end{array}$ & 6 & $\begin{array}{l}\text { Água, criança e árvore, esperança de um } \\
\text { dia melhor. }\end{array}$ \\
\hline \multirow{4}{*}{$\begin{array}{l}\text { Meio ambiente como projeto } \\
\text { comunitário entendido como lugar } \\
\text { de cooperação e de parceria }\end{array}$} & 7 & $\begin{array}{l}\text { Já tem água, já tem luz, agora só falta o } \\
\text { esgoto. }\end{array}$ \\
\hline & 8 & $\begin{array}{l}\text { Nossa horta, o pai fez a caixa e nós } \\
\text { plantamos. }\end{array}$ \\
\hline & 10 & $\begin{array}{l}\text { Essa lixeira precisa mudar e essa mudança } \\
\text { depende de nós }\end{array}$ \\
\hline & 12 & $\begin{array}{l}\text { A reciclagem precisa melhorar ser mais } \\
\text { organizada }\end{array}$ \\
\hline
\end{tabular}

Entendemos que quatro legendas correspondem a dimensão de meio ambiente como projeto comunitário, por expressarem a ideia de trabalho coletivo, de organização da comunidade para a instalação de infraestrutura e melhorias como a organização dos recicladores que ocupas as ruas da vila com suas coletas. Esta dimensão se aproxima muito da dimensão meio ambiente como problema a ser resolvido, pois expressa o desejo de mudança, melhoria do ambiente onde se vive, no entanto essas legendas apenas apontaram problemas, sem expressar propostas ou disposição pessoal, para a resolução desses problemas.

A ideia de meio ambiente como recurso a ser gerido e repartido também esta presente nas legendas, relacionada ao plantio de alimentos, a reciclagem e a utilização de animais como cavalo para transporte e trabalho. Já a ideia de natureza para se apreciar, preservar e respeitar foi identificada em duas fotografias, assim como a de meio ambiente como lugar onde se vive, esta ultima também está muito próxima da ideia de projeto 
comunitário pois pode motivar a partir do sentimento de pertencimento a participação comunitária.

A categoria meio ambiente biosfera foi identificada em uma legenda que fez menção ao futuro "esperança de um dia melhor". A categoria meio ambiente como sistema a compreender e decidir melhor não foi identificada em nenhuma legenda.

\section{CONSIDERAÇÕES}

Compreender a realidade concreta da comunidade da vila Santo André foi de fundamental importância para a organização das ações de educação ambiental voltadas para aquele público, além disso na dinâmica de entrevistas e oficina aqui relatadas foi possível construir uma relação dialógica com a comunidade.

Podemos perceber através das fotos e legendas uma grande preocupação dos moradores em relação a resolução de problemas e de fato a comunidade tem muitos problemas a serem resolvidos, mas as imagens também revelaram a presença do espírito de cooperação e parceria fundamentais para a resolução dos problemas identificados. Nesse sentido, nosso papel como educadoras foi o de estimular e fomentar a união e organização dos moradores, partindo da ideia de mobilização local até a de cidadania planetária.

A vila Santo André de forma geral entende que o meio ambiente primeiramente deve ser um lugar com condições de se viver com dignidade e qualidade de vida e estão se organizando para conquistar este direito. Esta é a representação social que se aplica a realidade dessa comunidade, talvez a vila vizinha perceba de outra forma o meio ambiente, então de fato essa experiência convidou os moradores da vila a refletirem sobre o ambiente em que estão inseridos e fazem parte, gerou discussões, trocas de informações e conhecimento e como produto construíram coletivamente um conceito próprio de meio ambiente revelando-se como um espaço educativo e democrático fora dos limites da escola.

A representação social revelada através das fotos nos fez perceber que mesmo se tratando de ações teoricamente voltadas para uso consciente da água, temas relacionado a reciclagem e organização comunitária teriam que ser contemplados de alguma forma. Pois falar de uso consciente da água em uma comunidade onde o esgoto corre a céu aberto sem problematizar a questão e a necessidade de mobilização dos moradores para que exijam da administração pública municipal providências é impossível do ponto de vista de uma educação comprometida com a transformação social como a educação ambiental deve ser. 
Assim consideramos que a representação social de meio ambiente é uma ótima ferramenta a ser utilizada em trabalhos de educação ambiental como metodologia para diagnóstico participativo e base para o planejamento de ações posteriores.

\section{REFERÊNCIAS}

ANA. Divisão Hidrográfica Nacional 2008. Disponível em: www.ana.gov.br

Diagnóstico Ambiental de Porto Alegre: Geologia, Solos, Drenagem, Vegetação/Ocupação e paisagem. Porto Alegre: Secretaria Municipal do meio Ambiente, 2008

BRANDÃO, Carlos, Rodrigues; STECK, Danilo Romeu. Pesquisa participante: a partilha do saber. In: BRANDÃO, C. R.; STECK, D.. (Org.). Pesquisa participante: o saber da partilha. São Paulo, Aparecida: Idéias e Letras, 2006. 295 p.

MOSCOVICI, Serge. Prefácio. In GUARESCHI, Pedrinho \& JOVCHLOVITCH, Sandra (org.). Textos em representações sociais. Petrópolis, RJ: Vozes, 1995.

MOURA, Eliana Perez Gonçalvez de; ZUCHETTI, Dinora Tereza; MENEZES, Magali Mendes de. Práticas de educação não escolar entre a precarização e a profissionalização. In: Trabalho \& Educação. Belo Horizonte, v.23, n.3, p. 87-100 set-dez, 2014.

MOURA, Eliana Perez Gonçalves de e ZUCCHETTI, Dinora Tereza. Educação além da escola: acolhida a outros saberes. In: Cadernos de Pesquisa. vol.40 n.140. São Paulo: maio/ago. 2010.

REIGOTA, Marcos. Meio Ambiente e Representação Social. 8ed. São Paulo: Cortez, 2010

SEVERO, José Leonardo Rolim de Lima. Educação não escolar como campo de práticas pedagógicas. In: Revista Brasileira de Estudos Pedagógicos (online), Brasília, v. 96, n. 244, p. 561-576, set./dez. 2015.

GOHN, Maria da Glória. Educação não formal e o educador social: atuação no desenvolvimento de projetos sociais. São Paulo: Cortez, 2010.

SAUVÉ, Lucie. Educação Ambiental: possibilidades e limitações. Educação e Pesquisa, São APulo, v.31, n2, p.317-322, mai/ago:2005 